Article

\title{
Agricultural Health and Safety Survey in Friuli Venezia Giulia
}

\author{
Sirio Rossano Secondo Cividino *, Gianfranco Pergher, Nicola Zucchiatti and Rino Gubiani \\ Department of Agricultural, Food, Environmental and Animal Sciences, University of Udine, \\ via delle Scienze 206, 33100 Udine, Italy; gianfranco.pergher@uniud.it (G.P.); \\ nicola.zucchiatti@uniud.it (N.Z.); rino.gubiani@uniud.it (R.G.) \\ * Correspondence: agricolturasicura@gmail.com; Tel.: +39-3281547453
}

Received: 17 October 2017; Accepted: 18 December 2017; Published: 8 January 2018

\begin{abstract}
The work in the agricultural sector has taken on a fundamental role in the last decades, due to the still too high rate of fatal injuries, workplace accidents, and dangerous occurrences reported each year. The average old age of agricultural machinery is one of the main issues at stake in Italy. Numerous safety problems stem from that; therefore, two surveys were conducted in two different periods, on current levels of work safety in agriculture in relation to agricultural machinery's age and efficiency, and to show the levels of actual implementation of the Italian legislation on safety and health at work in the agricultural sector. The surveys were carried out, considering a sample of 161 farms located in the region Friuli Venezia Giulia (North-East of Italy). The research highlights the most significant difficulties the sample of farms considered have in enforcing the law. One hand, sanitary surveillance and workers' information and training represent the main deficiencies and weakest points in family farms. Moreover, family farms do not generally provide the proper documentation concerning health and safety at workplaces, when they award the contract to other companies. On the other hand, lack of maintenance program for machinery and equipment, and of emergency plans and participation of workers' health and safety representative, are the most common issues in farms with employees. Several difficulties are also evident in planning workers' training programs. Furthermore, the company physician's task is often limited to medical controls, so that he is not involved in risk assessment and training. Interviews in heterogeneous samples of farms have shown meaningful outcomes, which have subsequently been used to implement new databases and guidelines for Health and Safety Experts and courses in the field of Work Safety in agriculture. In conclusion, although the legislation making training courses for tractor operators and tractor inspections compulsory dates back to the years 2012 and 2015, deadlines have been prorogued, and the law is not yet fully applied, so that non-upgraded unfit old agricultural machinery is still being used by many workers, putting their health and their own lives at risk.
\end{abstract}

Keywords: work safety; health and safety; risk prevention; risk assessment document; ROPS; safety belt

\section{Introduction}

In the last decades, the theme of safety at work in the agricultural sector has taken on a fundamental role. Following the 'Tractor Directive' in Italian law on Safety at work (Italian Law 81/2008) - agricultural tractors are currently equated to work machines, the principles of safety at work, ergonomics, and protection of the tractor operator and the other passengers [1,2].

Agricultural tractors in Italy are estimated in 1.7 million units, $35 \%$ of which are older than 44 years of age and $50 \%$ of which are older than 25 years of age [3]. This is a considerably critical issue in the field of road traffic and safety at work. 
Despite many projects and awareness campaigns concerning the issue of safety in agricultural activities, conducted particularly by the National Institute for Insurance against Accidents at Work, vehicles, being non-compliant and potentially fatal in the event of an accident [4-6], are still present in farms and on the market. Many case studies [7-10] show that tractors lacking essential safety requirements-like seat belts and Roll Over Protection Systems-can cause fatal accidents in case of roll-over of the vehicle [1].

Accidents caused by and with tractors are statistically one of the most frequent causes of death in agriculture $[1,11,12]$.

In Italy, the underestimation of this phenomenon has been observed for many years; in fact, only accidents involving farm employees were registered as 'occupational accidents' until 2014, while those involving semi-professional operators were considered as 'domestic accidents' [1].

According to a recent study on serious accidents in agriculture in Friuli Venezia Giulia (North East of Italy), an estimated rate of $30 \%$ cases are not surveyed or investigated [1,3]. Considering only the deadly accidents in agriculture and forestry operations, concern arises, as $51 \%$ of these accidents happened while workers were operating tractors ( $75 \%$ located on field and $25 \%$ while driving on roads) $[4,13,14]$.

As far as accident dynamics are concerned, machine rollover represents $77 \%$ of accidents, while accidents involving the cardan shaft account for $0.7 \%$ only, but $66 \%$ of cases result in the death of the operator $[15,16]$.

According to the reconstruction of 60 fatal accidents with tractors (northeast Italy) [2,11], the origin of these accidents can be categorized into three types:

- Technical causes (set of lacking safety elements)

- Causes of a human or behavioral nature (improper use of the tractor). In this regard it should be stressed that the legislation does not provide the private use of the tractor, it must always be linked to the cultivation or the forest; this is a factor that is often missing in the use of such equipment, in fact, as shown in the analyzed data in five cases the tractor was used in non-agricultural contexts and with playful purposes (race of tractors, carnival parade, loading and unloading of building material, and transport with tractor of building vehicles) $[2,11]$

- Structural failures (within the analyzed cases, some of them are related to the failure of embankments, bridges or ditches) [2,11].

However, it should be stressed that in the reconstruction of the dynamics, often there is not only one cause but the fatal accident is derived from a human error combined with the use of an unsafe vehicle. [2,11,12].

Within the European Community and according to Italian norms, there is currently a decisive indication by the legislator to make the use of agricultural tractors more professional and more responsible in considering other sectors as the plants to energy conversions and agro industrial [11,12,17-21].

Since 2012, with the 'Technical Law' bill, a specific professional training for the use of this type of machinery has been implemented as mandatory - an obligation that is still to be fully extended within the Italian territory $[15,19,22]$.

In the light of such considerations, this study is meant to investigate a representative sample of the real conditions of the tractors within farms, aiming at bringing to light the main criticalities and proposing effective systems of analysis that can be used by the agricultural entrepreneurs themselves, to improve the present situation.

\section{Materials and Methods}

A first-level analysis was conducted to assess safety levels on a sample of 103 agricultural farms, with a prevalence of dairy farms and farms with vineyard and/or horticultural crops (Table 1). 
Table 1. The sample farms in the first survey.

\begin{tabular}{cccc}
\hline Type of Farm & No. & \% & Average Size (ha) \\
\hline Dairy farms & 36 & 35.0 & 67.5 \\
Other livestock & 17 & 16.5 & 89.9 \\
Vineyard and winery & 24 & 23.3 & 55.6 \\
Horticulture and nursery & 12 & 11.7 & 9.4 \\
Other & 7 & 6.8 & 14.9 \\
Mixed & 4 & 3.9 & 240.5 \\
Cereal crops & 3 & 2.9 & 42.3 \\
All farms & 103 & 100.0 & 63.9 \\
\hline
\end{tabular}

These farms were located in all of the six Health Districts in Friuli Venezia Giulia, each controlled by the respective District Agency. Part of these farms (56.3\%) employed hired personnel, while 43.7\% were family farms, allowed by the law to use a simplified safety management scheme.

Each farm was visited by one evaluator, and all data were recorded following a specific questionnaire. This questionnaire covered two main areas of interest (Figure 1):

- $\quad$ area $\mathrm{A}$, including general information about the farm;

- $\quad$ area B, which varied depending on farm specialization, and was further divided into three profiles:

B1: farm machinery;

B2: personal protective equipment (PPE);

B3: specific risks.

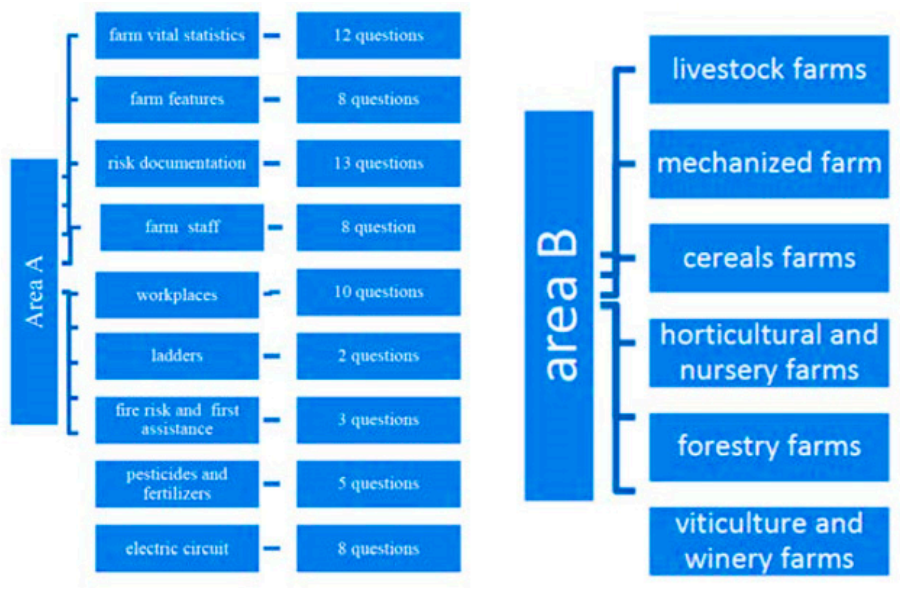

Figure 1. Specific questionnaire.

A second-level analysis was performed on a sample of 58 agricultural tractors (Table 7), employed in 11 selected farms, with the objective of further analyzing the presence or absence of legally required protective items. All main protective equipment and safety systems', as mentioned at point 2.4 part II of Annex V of the Italian Law number 81/2008, were checked and evaluated for compliance with the law. This included roll-over protective structures, safety belts, protections of moving parts, and other items (reported in Table 9).

\section{Results}

To the purpose of the first study, we analyzed:

- whether official documents and records were actually present at the farm; 
- $\quad$ how safety management was organized;

- $\quad$ the working environment in the farm (useful element to correlate machine use and safety);

- $\quad$ the presence of protection devices on tractors;

- $\quad$ the use of prevention and protection equipment.

\subsection{First Level Analysis}

Table 2 includes only 58 farms with external personnel, which are subjected to full application of Italian Law 81/08, including official documentation. The main document required, i.e., the Risk assessment document, was absent or inadequate in $34.5 \%$ of the farms; other required documents were even more often missing, including a scheme for medical surveillance of workers (34.5\%), the scheme for emergency procedures (41.4\%), and the record of periodic inspection of lifting equipment $(44.8 \%)$.

Table 2. Official documents at the farm.

\begin{tabular}{cc}
\hline Type of Document & Missing or Inadequate (\% of Farms) \\
\hline Risk assessment document & 34.5 \\
Risk assessment update & 44.8 \\
Medical watch & 34.5 \\
Emergency procedures & 41.4 \\
Regular inspection record (lifting equipment) & 44.8 \\
Compliance certificate of equipment & 10.3 \\
Book of use and maintenance & 8.6 \\
Pesticide license & 24.1 \\
Pesticide safety sheet & 25.9 \\
Equipment maintenance plan & 36.2 \\
\hline
\end{tabular}

Only those documents provided by third parties were mostly present, such as the Compliance certificate (lacking in $10.3 \%$ of farms), the Book of use and maintenance of equipment $(8.6 \%)$, the Pesticide safety sheet (25.9\%), or those required for purchasing pesticides (Pesticide license: $24.1 \%$ ). Particularly remarkable was the absence of a plan for machinery and equipment maintenance (in $36.2 \%$ of farms), because of its great importance for accident prevention.

The Italian law also requires every farm with hired personnel to officially appoint a number of figures in charge of the different protection and prevention services (Table 3). While a safety manager (or head of the prevention and protection service, PPS) was mostly present ( $82.8 \%$ of the farms), other figures were often missing, including a doctor designated for periodic medical surveillance $(48.1 \%$ of farms), or the supervisors for fire prevention (33.3\%), first aid (34.6\%) and workers' safety during work $(63.0 \%)$. Additionally, $38.3 \%$ of the farms were not providing the workers with sufficient training and information services, while $44.3 \%$ did not have any special training for the various managers and supervisors.

Table 3. Managers and services.

\begin{tabular}{cc}
\hline & Not Present (\% of Farms) \\
\hline Safety manager & 17.2 \\
Medical doctor & 48.1 \\
Fire prevention manager & 33.3 \\
First-aid manager & 34.6 \\
Workers' supervisor & 63.0 \\
Training and information service (workers) & 38.3 \\
Special training service (managers) & 44.3 \\
\hline
\end{tabular}

Most of the farms had adequate toilet and shower services and dressing rooms for the workers (Table 4). The width of the main entrance to the farm (minimum: $5 \mathrm{~m}$ ) was mostly in line with the law. 
However, protections on gaps or trenches were missing in $28 \%$ of the farms. Most remarkable was the absence of any Interference risk analysis, i.e., a plan to avoid risks owing to the presence at the farm of external personnel, especially contractors for cereal or grape harvesting. Only $8.6 \%$ of farms had conducted a proper analysis of such risks.

Table 4. Situation of buildings in the farm.

\begin{tabular}{ccc}
\hline Building Services & Yes (\%) & No (\%) \\
\hline Toilets & 93.9 & 6.1 \\
Showers & 87.2 & 12.7 \\
Dressing room & 86.4 & 13.5 \\
Main entrance to farm $>5 \mathrm{~m}$ & 81.3 & 18.6 \\
Railing on hole, trench & 71.8 & 28.1 \\
Interference risk analysis & 8.6 & 91.4 \\
\hline
\end{tabular}

In approx. one half of the farms, a specific analysis was made to assess the main features of the tractors (Table 5). The average nominal power was $63 \mathrm{~kW}$, and the average age was 20.9 years. The average annual usage ( $328 \mathrm{~h}$ /year) was related to the small average land area (63.9 ha, Table 1), and was far from the level suggested for profitable management (at least $600 \mathrm{~h} /$ year). These data offer some clues as to the current difficult economic situation in most of the farms: the reasons are many, and they cannot be fully discussed here. Nonetheless, this makes it even more difficult for these farms to bear the costs involved by current requirements for risk prevention and protection.

Table 5. Tractors at the farms.

\begin{tabular}{cccccc}
\hline & No. of Tractors & Power $\mathbf{( k W )}$ & Age (years) & Usage (h) & Usage (h/year) \\
\hline Dairy farms & 54 & 76.6 & 20.7 & 7339 & 355 \\
Other livestock & 18 & 65.6 & 21.6 & 7078 & 328 \\
Viticulture & 62 & 57.1 & 15.3 & 4444 & 290 \\
Horticulture and nursery & 26 & 50.3 & 27.8 & 3610 & 130 \\
Other & 2 & 40.4 & 24.8 & 1750 & 71 \\
Mixed & 29 & 61.8 & 26.1 & 15329 & 588 \\
Cereal crops & 5 & 64.7 & 20.0 & 6958 & 348 \\
All farms & 196 & 63.1 & 20.9 & 6873 & 328 \\
\hline
\end{tabular}

In fact, missing protection devices are mostly related to the tractor's old age. In most of the sample farms, tractors were equipped with roll over protection structures (ROPS), protection of moving parts, such as belts and fans, and of hot surfaces (Table 6). However, a safety belt was missing at the driver's seat in $55.1 \%$ of the tractors-even though it has been declared mandatory since 2005. PTO (power take off) guards were also missing in $24.7 \%$ of the tractors (the study has analyzed in a different and specific way the part of the PTO, as it is often the cause of fatal accidents).

The relationship between the presence of protective items and the tractor's age is shown in Figure 2. All of the new tractors were in line with legal requirements, the only exception being the safe access to the driver's seat; Italian law requires the presence of two handles and stairs for tractors that have a distance exceeding $0.55 \mathrm{~m}$ from the ground (Annex $\mathrm{V}$ of the Italian Law 81/08) but this is often difficult to attain especially in small tractors for viticulture. This means that the main problem for these farms is the low investment capacity, which makes it difficult for farmers to replace old tractors with new ones.

Figure 3 shows the percentages of farms providing their workers with personal protection equipment (PPE). In general, only basic PPE were present (like cotton overalls and mechanical protection gloves), while specific PPE were seldom found (such as ear muffs, safety foot-ware, chemical resistant clothing and gloves and chemical resistant respirators). 
Table 6. Protective devices.

\begin{tabular}{cc}
\hline Protective item & Missing $(\%$ of Tractors) \\
\hline ROPS & 5.2 \\
Safety belt & 55.1 \\
Protection of belts \& fans & 7.6 \\
Protection of hot surfaces & 10.8 \\
Safe access to driver seat & 13.6 \\
PTO guards & 24.7 \\
CE marking (European Conformity) & 37.6 \\
Owner handbook & 8.0 \\
\hline
\end{tabular}

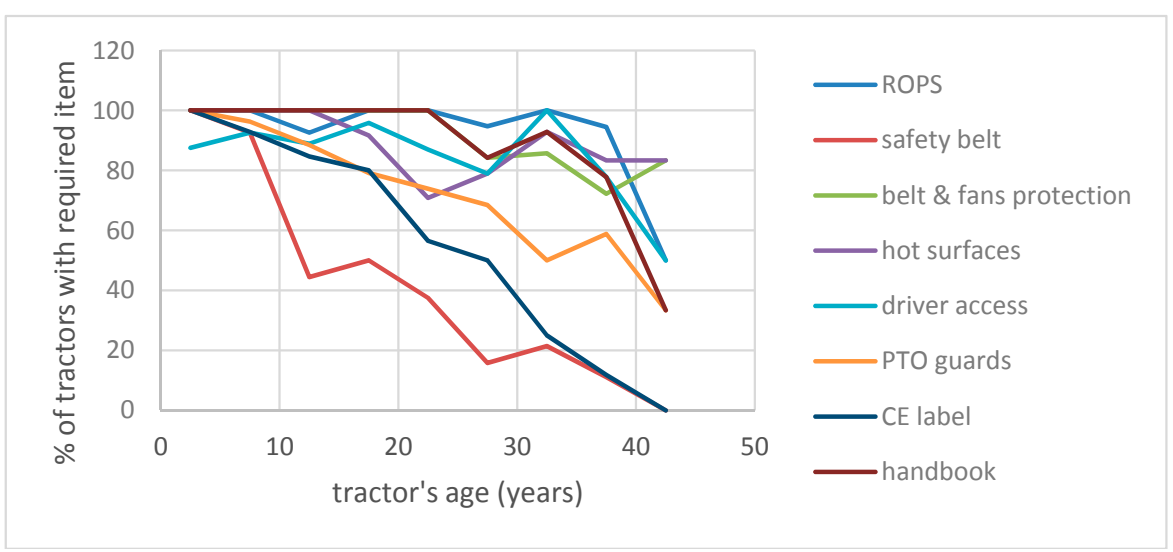

Figure 2. Tractors with required protective items in place.

The main findings from the survey suggested that several agricultural farms were sufficiently aware of the risks associated either with their specific production systems, or with the machinery used, to some extent, particularly in order to avoid the related economic costs. More importantly, information about legal obligations was generally poor, as was the understanding of the possible cost, in terms of fines, damage compensations etc. which failure to comply with the rules might cause.

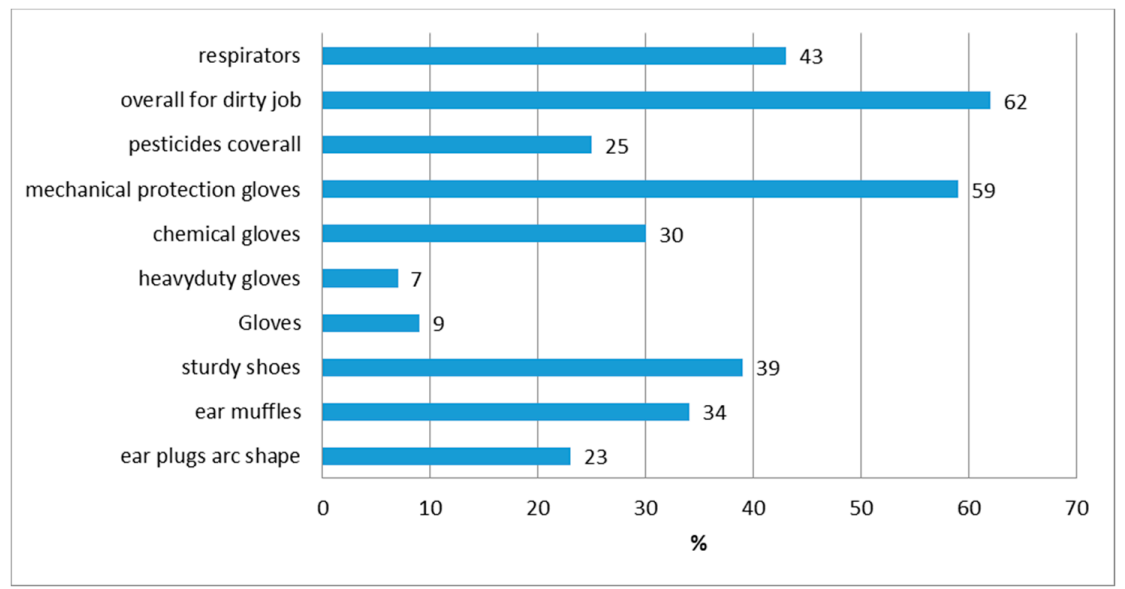

Figure 3. Types of personal protective equipment (PPE) provided at the farms (\% of farms where present).

This suggested that most farms would take advantage of some simple informative tool, e.g., in the form of a software, to quickly detect the most critical situations. This software, based on a Microsoft Excel ${ }^{\circledR}$ worksheet (Figure $4 a$ ), enables the farmer to check all of the legal requirements for tractors and the main agricultural implements, and suggests how to amend possible defects. 
For instance, it is possible to examine the existing ROPS on a tractor (Figure $4 \mathrm{~b}$ ), and understand whether it fulfills legal requirements or it needs changes or replacement; furthermore, indications may be given on how to install a ROPS on an old tractor.

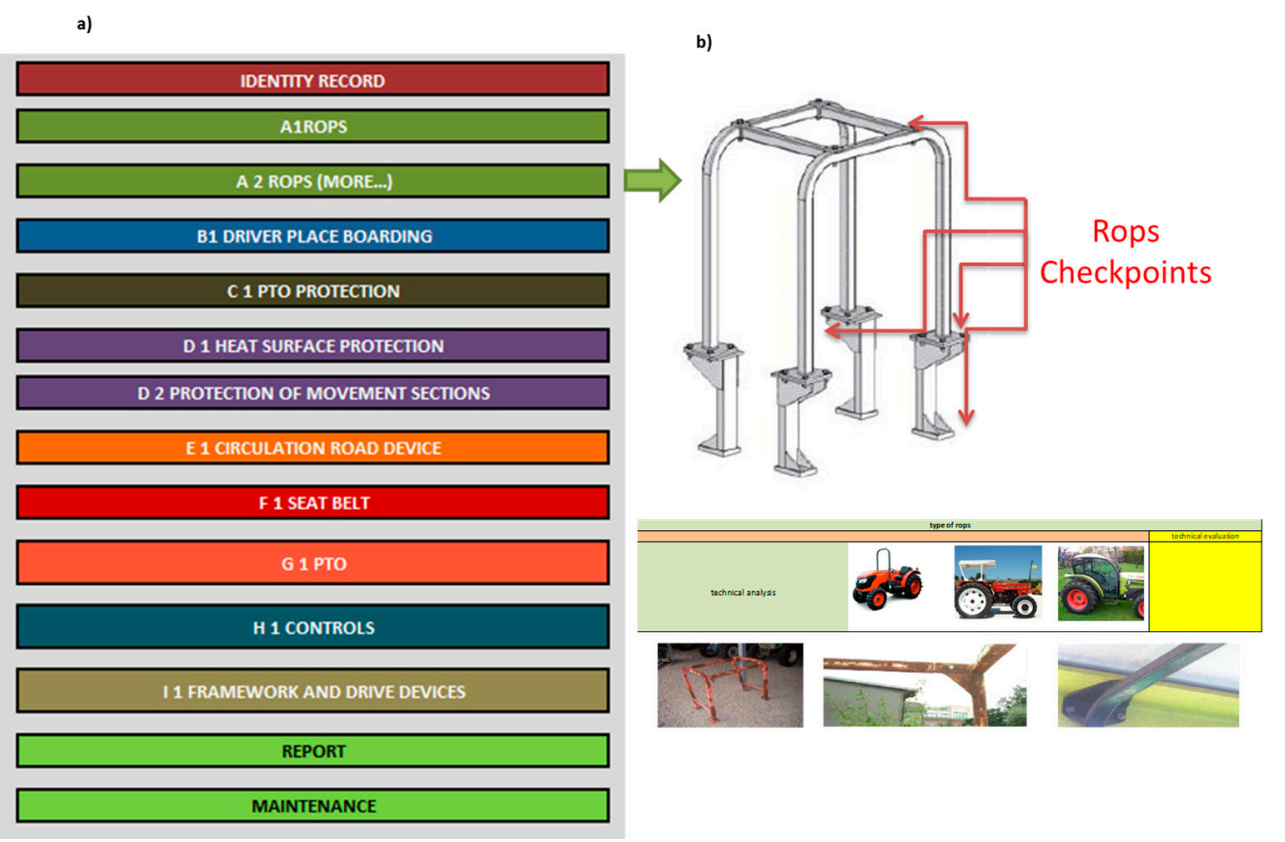

Figure 4. Extract from the software designed for the analysis of the tractors (a), (b) specific ROPS (rollover protection system) control areas.

\subsection{Second-Level Analysis of the Sample Based on 11 Farms}

The second survey investigated three groups of farms: vineyard farms, cattle and cereal farms, and a third group of mixed farms (Table 7). This involved an overall number of 58 agricultural tractors.

Table 7. The sample farms in the second survey.

\begin{tabular}{ccccc}
\hline Farm & Type & Own Area, ha & Managed Area, ha & Managed Area, ha \\
\hline 1 & Vineyard & 180 & 180 & 18 \\
3 & Vineyard & 15 & 30 & 4 \\
5 & Vineyard & 50 & 50 & 4 \\
8 & Vineyard & 5 & 5 & 2 \\
\hline \multicolumn{7}{c}{ Vineyard farms } & & & 28 \\
\hline 2 & Cattle and Cereals & 50 & 200 & 5 \\
4 & Cattle and Cereals & 60 & 80 & 5 \\
11 & Cattle and Cereals & 20 & 70 & 3 \\
\hline \multicolumn{7}{c}{ Cattle \& Cereals Farms } & & & 13 \\
\hline 6 & Cereals and Contractor & 300 & 450 & 7 \\
9 & Orchard & 5.8 & 5.8 & 2 \\
10 & Mixed & 50 & 250 & 5 \\
\hline Total & Market garden & 2 & 3 & 3 \\
\hline
\end{tabular}

In the vineyard sector, the mean age of tractors was lower (5728 total $\mathrm{h}$ and 14.2 years) compared with both the Cattle \% Cereals group ( $8046 \mathrm{~h}$ and 25.2 years) and with the average of the remaining 
farms ( $8557 \mathrm{~h}$ and 24.3 years) (Table 8 ). On the other side, the annual use is higher in the vineyard sector (502 h/year, versus 351-370 h/year).

Table 8. Second survey: Tractors power, age and usage.

\begin{tabular}{ccccc}
\hline Type of Farms & Vineyard & Cattle \& Cereals & Other & All \\
\hline Rated power, $\mathrm{kW}$ & 56 & 59 & 65 & 59 \\
Age, $\mathrm{h}$ & 5729 & 8046 & 8557 & 7078 \\
Annual usage, h/year & 502 & 351 & 370 & 429 \\
Age, years & 14.2 & 25.2 & 24.3 & 19.6 \\
\hline
\end{tabular}

The fact that agricultural tractors in the vineyard sector are generally of a younger age implies that they have minor problems in terms of safety and efficiency. In fact, this particular agricultural sector is generally more proactive and prone to invest financial resources, mainly because companies have a higher profitability but also because they are normally larger and therefore more structured and less family-owned. This shows a clearer perception and higher awareness of safety issues and needs (Table 8). Nonetheless, the present study also highlights some extremely important negative features, which can be of paramount importance in implementing corrective measures for the upgrading of current agricultural machinery inventories. In fact, farms dealing with working areas of more than 50 ha extension have been recognized as having the oldest agricultural tractors-with an average age of 25 years.

The main lack is in the power take-off guards (34.5\%), followed by driver's seat belts $(24.1 \%)$, together with lack of hot parts protective shields (32.8\%). Lack of moving parts protections $(20.7 \%)$ and ROPS (19\%) has also been highlighted by the study (Table 9 ).

Table 9. Compliance with safety requirements (\% of all tractors). Study-derived technical analysis.

\begin{tabular}{|c|c|c|c|}
\hline Item & Evaluation & Yes & No \\
\hline Documents & Compliant & 69.0 & 31.0 \\
\hline PTO guards & Compliant & 65.5 & 34.5 \\
\hline Moving parts, protections & Compliant & 79.3 & 20.7 \\
\hline Hot surfaces, protection & Compliant & 63.8 & 32.8 \\
\hline \multirow{2}{*}{ ROPS } & Compliant & 81.0 & 19.0 \\
\hline & Present & 98.3 & 1.7 \\
\hline \multirow{3}{*}{ Driver's seat } & Compliant & 50.0 & 50.0 \\
\hline & Type conform & 69.0 & 31.0 \\
\hline & Undamaged & 75.9 & 24.1 \\
\hline \multirow{4}{*}{ Handles } & Compliant & 72.4 & 27.6 \\
\hline & Present & 77.6 & 22.4 \\
\hline & Type compliant & 74.1 & 25.9 \\
\hline & Size compliant & 72.4 & 27.6 \\
\hline \multirow{3}{*}{ Stairs } & Compliant & 84.5 & 15.5 \\
\hline & Present & 94.8 & 5.2 \\
\hline & Size compliant & 84.5 & 15.5 \\
\hline \multirow{4}{*}{ Safety belt } & Compliant & 67.2 & 32.8 \\
\hline & Present & 75.9 & 24.1 \\
\hline & Own installation & 22.4 & \\
\hline & Own installation, certified & 8.6 & \\
\hline \multirow{3}{*}{ Tires } & Compliant & 69.0 & 31.0 \\
\hline & Type compliant & 82.8 & 15.5 \\
\hline & Undamaged & 77.6 & 22.4 \\
\hline Mirrors & Compliant & 69.0 & 31.0 \\
\hline Lights & Compliant & 75.9 & 24.1 \\
\hline
\end{tabular}


Tractor's compliance with the law (\% of required items that were indeed present) was analyzed versus the tractor's age (in years) and the type of farm personnel (farms with and without external, hired workers, respectively). Both regressions in Figure 5 were statistically significant $\left(R^{2}=0.383\right.$ and $R^{2}=0.453$, respectively), showing that: in general, the percentage of compliant items decreased with increased age of the tractors; in particular, tractor compliance was lower in family farms independently of the tractor's age. This can be explained by lower perception of risks in family farms, which certainly represents a failure of awareness campaigns conducted so far, but may also be related to the smaller economic size of these farms, and to the difficulty of bearing the costs involved by extensive equipment updating so as to meet the current requirements for risk prevention and protection.

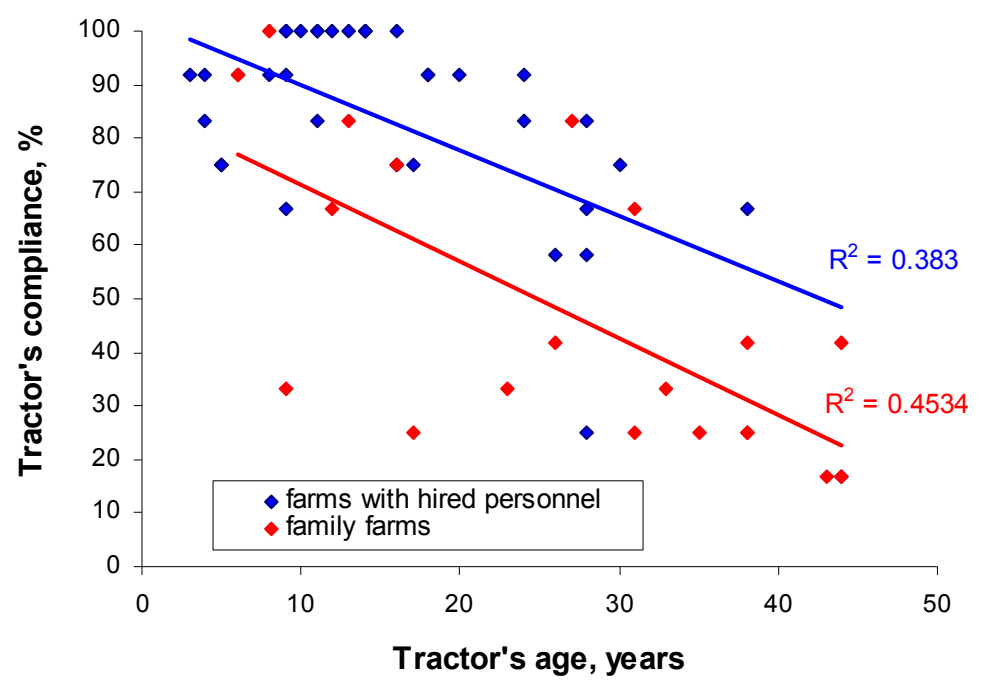

Figure 5. Tractor's compliance (\% of compliant items) vs. tractor's age (years) in farms with or without hired personnel.

\section{Conclusions}

This research work shows that the situation of safety in the agricultural sector is still a real cross-cutting issue, mainly due to three aspects:

- low perception and awareness of the issue of safety at work by the workers in the agricultural sector; in fact, even if the machines are technically obsolete and unsafe, there is the tendency not to sell or adjust the machine, which is considered as a potentially useful vehicle or one that can be used in case of emergency.

- non-economical difficult interventions to upgrade machines having mainly a non-productive, affective value; in fact, very often the agricultural entrepreneur does not want to discard his own machine since the tractor is linked to a memory of a missing family member or parents.

- $\quad$ ineffective control system (e.g., [3,8,10,13,20-22]).

With the introduction of a rapid and efficient control system, this study wants to propose an operational instrument enabling the farmer to analyze the farm machinery and to put into practice simple modifications or installations that in the case of an accident or tipping of the machine could mean saving his/her life. The instrument could also be an excellent guideline not only for the agricultural world but also for the workshops that are only currently approaching the problem of the adjustment of agricultural machinery.

Moreover, the study only concentrated on the harmonized safety standard for the tractors improved safety for operators, such as physical exposure to ergonomic hazards. In fact, operators loading the machines are prone to musculoskeletal disorders since they often undergo awkward 
postures, repetitive movements and frequent lifting of loads. For this reason, further studies in this matter in particular could prove useful.

In particular, this study highlights the fact that, although the legislation making training courses for tractor operators and tractor inspections compulsory dates back to the years 2012 and 2015, deadlines have been postponed and the law is not yet fully applied.

Acknowledgments: Our research work was supported by funds received from the National Institute for Insurance against Workplace Accidents and Occupational Disease.

Author Contributions: Sirio Rossano Secondo Cividino and Rino Gubiani evaluated the technical aspects of safety and accidents in farms; Gianfranco Pergher conceived and designed the experiments and methodology, Nicola Zucchiatti followed the graphic design. Gainfranco Pergher and Sirio Rossano Secondo Cividino wrote the paper.

Conflicts of Interest: The authors declare no conflict of interest.

\section{References}

1. Thelin, A. Fatal accidents in Swedish farming and forestry, 1988-1997. Saf. Sci. 2002, 40, 501-517. [CrossRef]

2. Cividino, S.; Gubiani, R.; Vello, M.; Pergher, G.; Grimaz, S. Sicurezza sul lavoro: Criticità nell'azienda Agricola. L'inf. Agrar. 2016, 24, 30-33.

3. Fargnoli, M.; Laurendi, V.; Tronci, M. Design for Safety in Agricultural Machinery. In Proceedings of the International Design Conference-Design, Dubrovnik, Croatia, 17-20 May 2010.

4. INAIL. Istituto Nazionale per L'assicurazione Contro Gli Infortuni Sul Lavoro. Available online: www.inail.it (accessed on 1 May 2015).

5. $\quad$ Etherton, J.R.; Myers, J.R.; Jensen, R.C.; Russel, J.C.; Braddee, R.W. Agricultural Machine-Related Deaths. Am. J. Public Health 1991, 81, 766-768. [CrossRef] [PubMed]

6. Fulcher, J.; Noller, A.; Kay, D. Framing tractor fatalities in Virginia: An 11-year retrospective review. Am. J. Forensic Med. Pathol. 2002, 33, 377-381. [CrossRef] [PubMed]

7. Rete Rurale Nazionale. Prevenzione e Sicurezza Sul Lavoro in Agricoltura: Conoscenze e Costi per le Aziende Agricole. Ministero Delle Politiche Agricole Alimentari e Forestali, Dipartimento Delle Politiche Europee ed Internazionali e Dello Sviluppo Rurale. Available online: www.reterurale.it (accessed on 1 May 2016).

8. Seifert, A.L.; Santiago, D.C. Preparation of professionals in the area of agrarian sciences regarding safety in rural work. Cienc. Agrotecnol. 2009, 33, 1131-1138. [CrossRef]

9. Dogan, K.H.; Dermici, S.; Sunam, G.S.; Deniz, I.; Gunaydin, G. Evaluations of Farm Tractor-Related Fatalities. Am. J. Forensic Med. Pathol. 2010, 31, 64-68. [CrossRef] [PubMed]

10. Prošrekl, J. Safe behavior and level of knowledge regarding safe work practices on farms. Res. J. Chem. Sci. 2011, 1, 15-19.

11. Moreschi, C.; Da Broi, U.; Fanzutto, A.; Cividino, S.; Gubiani, R.; Pergher, G. Medicolegal Investigations into Deaths Due to Crush Asphyxia after Tractor Side Rollovers. Am. J. Forensic Med. Pathol. 2017, 38, 312-317. [CrossRef] [PubMed]

12. Rees, W.D. Agricultural tractor accidents: A description of 14 tractor accidents and a comparison with road traffic accidents. Br. Med. J. 1965, 2, 63-66. [CrossRef] [PubMed]

13. Cole, H.P.; Myers, M.L.; Westneat, S.C. Frequency and severity of injuries to operators during overturns of farm tractors. J. Agric. Saf. Health 2006, 12, 127-138. [CrossRef] [PubMed]

14. Monarca, D.; Cecchini, M.; Guerrieri, M.; Colantoni, A. Conventional and alternative use of biomasses derived by hazelnut cultivation and processing. Acta Hortic. 2009, 845, 627-634. [CrossRef]

15. Kelsey, T.W.; May, J.J.; Jenkins, P.L. Farm tractors, and the use of seat belts and roll-over protective structures. Am. J. Ind. Med. 1996, 30, 447-451. [PubMed]

16. Hyland-Mcguire, P. Farm accidents involving power take-off devices. J. Accid. Emerg. Med. 1994, 11, $121-124$. [CrossRef] [PubMed]

17. Monarca, D.; Cecchini, M.; Colantoni, A. Plant for the production of chips and pellet: Technical and economic aspects of an case study in the central Italy. In Proceedings of the ICCSA 2011 International Conference on Computational Science and Its Applications, Santander, Spain, 20-23 June 2011; Volume 6785, pp. $296-306$. 
18. Moscetti, R.; Saeyes, W.; Keresztes, J.C.; Goodarzi, M.; Cecchini, M.; Monarca, D.; Massantini, R. Hazelnut Quality Sorting Using High Dynamic Range Short-Wave Infrared Hyperspectral Imaging. Food Bioprocess Technol. 2015, 8, 1593-1604. [CrossRef]

19. Monarca, D.; Colantoni, A.; Cecchini, M.; Longo, L.; Vecchione, L.; Carlini, M.; Manzo, A. Energycharacterization and gasification of biomass derived by hazelnut cultivation: Analysis of produced syngas by gas chromatography. Math. Probl. Eng. 2012, 2012, 102914. [CrossRef]

20. Colantoni, A.; Ferrara, C.; Perini, L.; Salvati, L. Assessing trends in climate aridity and vulnerability to soildegradation in Italy. Ecol. Indic. 2015, 48, 599-604. [CrossRef]

21. Marucci, A.; Monarca, D.; Cecchini, M.; Colantoni, A.; Cappuccuni, A. The heat stress for workers employed in laying hens houses. J. Food Agric. Environ. 2013, 11, 20-24.

22. Cutini, M.; Forte, G.; Maietta, M.; Mazzenga, M.; Mastrangelo, S.; Bisaglia, C. Safety-Critical Manuals for Agricultural Tractor Drivers: A Method to Improve Their Usability. Agriculture 2017, 7, 67. [CrossRef]

(C) 2018 by the authors. Licensee MDPI, Basel, Switzerland. This article is an open access article distributed under the terms and conditions of the Creative Commons Attribution (CC BY) license (http://creativecommons.org/licenses/by/4.0/). 